\title{
Effect of power-law ionic conductances in the Hodgkin and Huxley model
}

\author{
Fidel Santamaria \\ From 24th Annual Computational Neuroscience Meeting: CNS*2015 \\ Prague, Czech Republic. 18-23 July 2015
}

An increasing number of results show that the voltage and spiking activity of a neuron follows scale free adaptation. Under such conditions, the voltage, or firing rate, of a neuron cannot be characterized by a unique time constant, instead these processes are characterized by power-laws. Power-law behaviors suggest that the components responsible for the voltage are strongly interacting across temporal scales, slow processes affect the rates of fast processes and vice versa. We recently introduced the fractional leaky integrate-and-fire model, which we have used to replicate the firing rate activity of adapting cortical neurons [1]. Our results have shown that spike rate adaptation can be modeled by a fractional derivative of low order. Thus suggesting, a strong interaction across conductances in cortical neurons.

this work we decided to study the effects of power-law behavior in a biophysical model of spiking activity, the Hodgkin-Huxley model. The classical Hodgkin-Huxley model is described by

$$
C \frac{d V}{d t}=-\left(g_{m}\left(V-E_{\text {rest }}\right)+\sum_{i=1}^{N} g_{i}\left(V-E_{i}\right)\right)+I .
$$

where $\mathrm{C}$ is the capacitance; $\mathrm{V}$, voltage; $\mathrm{g}_{\mathrm{m}}$, the membrane conductance; $E_{\text {rest }}$, the resting potential; $g_{i}=\left\{g_{\mathrm{Na}}\right.$, $\left.\mathrm{g}_{\mathrm{K}}\right\}$ the sodium or potassium conductances with corresponding reversal potentials $\left(E_{i}=\left\{E_{N a}, E_{K}\right\}\right)$; and $I$, the input curret. The conductances are $g_{K}=\overline{g_{K}} n^{4}$ and $g_{\mathrm{Na}}=\overline{g_{\mathrm{Na}}} m^{3} h$, with $\overline{g_{K}}$ and $\overline{g_{\mathrm{Na}}}$ the maximum conductances. The gating variables $\mathrm{n}, \mathrm{m}$, and $\mathrm{h}$ are defined by the general equation

$$
\frac{d x}{d t}=\alpha_{x}(V, t)(1-x)-\beta_{x}(V, t) x
$$

Correspondence: fidel.satamaria@utsa.edu

Wodimu TekaUTSA Neurosciences Institute, University of Texas at San Antonio, San Antonio, TX 78249, USA 


\section{Acknowledgements}

NSF DBI 1451032 (BRAIN-EAGER) and NSF EF 1137897

Published: 18 December 2015

\section{References}

1. Teka W, Marinov TM, Santamaria F: Neuronal Spike Timing Adaptation Described with a Fractional Leaky Integrate-and-Fire Model. PLoS Comput Biol 2014, 10(3):e1003526.

2. Marinov T, Ramirez N, Santamaria F: Fractional integration toolbox. fcaa 2013, 16(3):670-681.

doi:10.1186/1471-2202-16-S1-P250

Cite this article as: Santamaria: Effect of power-law ionic conductances in the Hodgkin and Huxley model. BMC Neuroscience 2015 16(Suppl 1): P250.

Submit your next manuscript to BioMed Central and take full advantage of:

- Convenient online submission

- Thorough peer review

- No space constraints or color figure charges

- Immediate publication on acceptance

- Inclusion in PubMed, CAS, Scopus and Google Scholar

- Research which is freely available for redistribution

Submit your manuscript at www.biomedcentral.com/submit
Ciomed Central 